\title{
CHARACTERISTICS OF SHOCK-COMPRESSED CONFIGURATION OF Ti AND Si POWDER MIXTURES
}

\author{
N.N. Thadhani, E. Dunbar," and R.A. Graham $\cdots$ \\ - Georgia Tech, School of Materials Science and Engineering, , Atlanta, GA 30062, \\ “New Mexico Tech, EMRTC, , Socorro, NM 87801, and \\ -..Sandia National Laboratories, Albuquerque, NM 87185.
}

Shock-compression recovery experiments were performed on mixtures of $\mathrm{Ti}$ and $\mathrm{Si}$ powders of fine, medium, and coarse morphology, and packed at different initial densities, using the Sandia Momma and Poppa Bear fixtures with Baratol explosive. The shock-compressed configuration revealed characteristics typical of either chemically reacted material with fine equiaxed grains, or unreacted material with densely packed $\mathrm{Ti}$ and $\mathrm{Si}$ particles. The unreacted configuration showed that $\mathrm{Ti}$ particles were extensively deformed, irrespective of powder morphology and shock conditions generated by either fixture. In contrast Si particles showed different characteristics depending on the powder morphology, packing density, and shock conditions. The microstructural characteristics of unreacted configuration of $\mathrm{Ti}$ and Si powder mixtures were investigated. Mechanistic processes occurring prior to the inception of shock-induced chemical reactions in this system are described.

Work supported by Sandia National Laboratories Document No. 42-5737 at New Mexico Tech, and also in part by the U.S. Army Research Office Contract \# DAAH04-93-G-0062 at Georgia Institute of Technology.

\section{INTRODUCTION}

Titarium-silicon represents an higly exothermic intermetallic forming system, with associated heat of reaction of $-138 \mathrm{kcal} / \mathrm{mole}$, volume change of $-27.8 \%$, and calculated reaction temperature of $2500 \mathrm{~K}$ for the formation of $\mathrm{Ti}_{5} \mathrm{Si}_{3}{ }^{1}$. Shock-compression experiments ${ }^{2}$ on Ti-Si powder mixtures have shown that chemical reactions in this system occur at shock pressures of only a few GPa, and corresponding bulk temperatures significantly below the melt temperature of $\mathrm{Si}$. The equilibrium shock temperature (and shock energy) does not influence the reaction behavior. Rather, by altering the shock pressure and initial packing density, but maintaining the same bulk temperature, it is found that the propensity for reaction initiation largely depends on particle size, with fine powder morphologies reacting at lower pressures and lower initial porosities ${ }^{2}$.

The objective of our present work is to study this system in detail via controlled instrumented and recovery experiments on the same types of powder mixtures and under similar loading conditions. The results of realtime measurements are discussed by Dunbar et $\mathrm{al}^{3}$ in this proceedings. Results of recovery experiments focussing on characteristics of shoci-compressed unreacted configuration of Ti-Si powder rixtures at conditions below the reaction threshold, will be described here.

\section{EXPERIMENTAL PROCEDURE}

Shock recovery experiments were performed on $\mathrm{Ti}-\mathrm{Si}$ powder mixtures of three types of powder morphologies, coarse (105-149 $\mu \mathrm{m}$ Ti and 45-149 $\mu \mathrm{m} \mathrm{Si}$, medium $(10-45 \mu \mathrm{m} \mathrm{Ti}$ and $\mathrm{Si})$, and fine $(1-3 \mu \mathrm{m} \mathrm{Ti}$ and $<5 \mu \mathrm{m} \mathrm{Si})$. The powders were mixed in a mortar and pestle (without organic mixing agents) in a volumetric distribution corresponding to the $\mathrm{Ti}_{5} \mathrm{Si}_{3}$ atomic stoichiometry compound. SEM images of the respective powder mixtures are shown in Fig. 1.

The various powder mixtures were shock loaded using the Sandiat Poppa Bear fixture with Baratol explosive (PB-B) and Momma Bear fixture with Baratol explosive (MB-B). In these fixtures the loading history is dominated by an initial low-pressure planar wave, followed by a radial wave focussing effect, resulting in peak pressures of $5 \pm 1$ GPa for PB-B system and $7.5 \pm$ $2.5 \mathrm{GPa}$ for MB-B system. ${ }^{4}$

Six experiments were performed on powder mixtures of medium morphology packed at initial density ranging between $53 \%$ to $64 \%$ (or porosity of $47 \%$ to $36 \%$ ) with MB-B fixture, and $45 \%$ to $53 \%$ (or porosity of $55 \%$ to $47 \%$ ) with PB-B fixture. Two experiments were performed on fine and coarse morphology powders, each with packing density of $64 \%$ (36\% porosity) with $\mathrm{MB}-\mathrm{B}$, and $53 \%$ (47\% porosity) with $\mathrm{PB}-\mathrm{B}$ fixture. 


\section{DISCLAIMER}

This report was prepared as an account of work sponsored by an agency of the United States Government. Neither the United States Government nor any agency thereof, nor any of their employees, makes any warranty, express or implied, or assumes any legal liability or responsibility for the accuracy, completeness, or usefulness of any information, apparatus, product, or process disclosed, or represents that its use would not infringe privately owned rights. Reference herein to any specific commercial product, process, or service by trade name, trademark, manufacturer, or otherwise does not necessarily constitute or imply its endorsement, recommendation, or favoring by the United States Government or any agency thereof. The views and opinions of authors expressed herein do not necessarily state or reflect those of the United States Government or any agency thereof. 

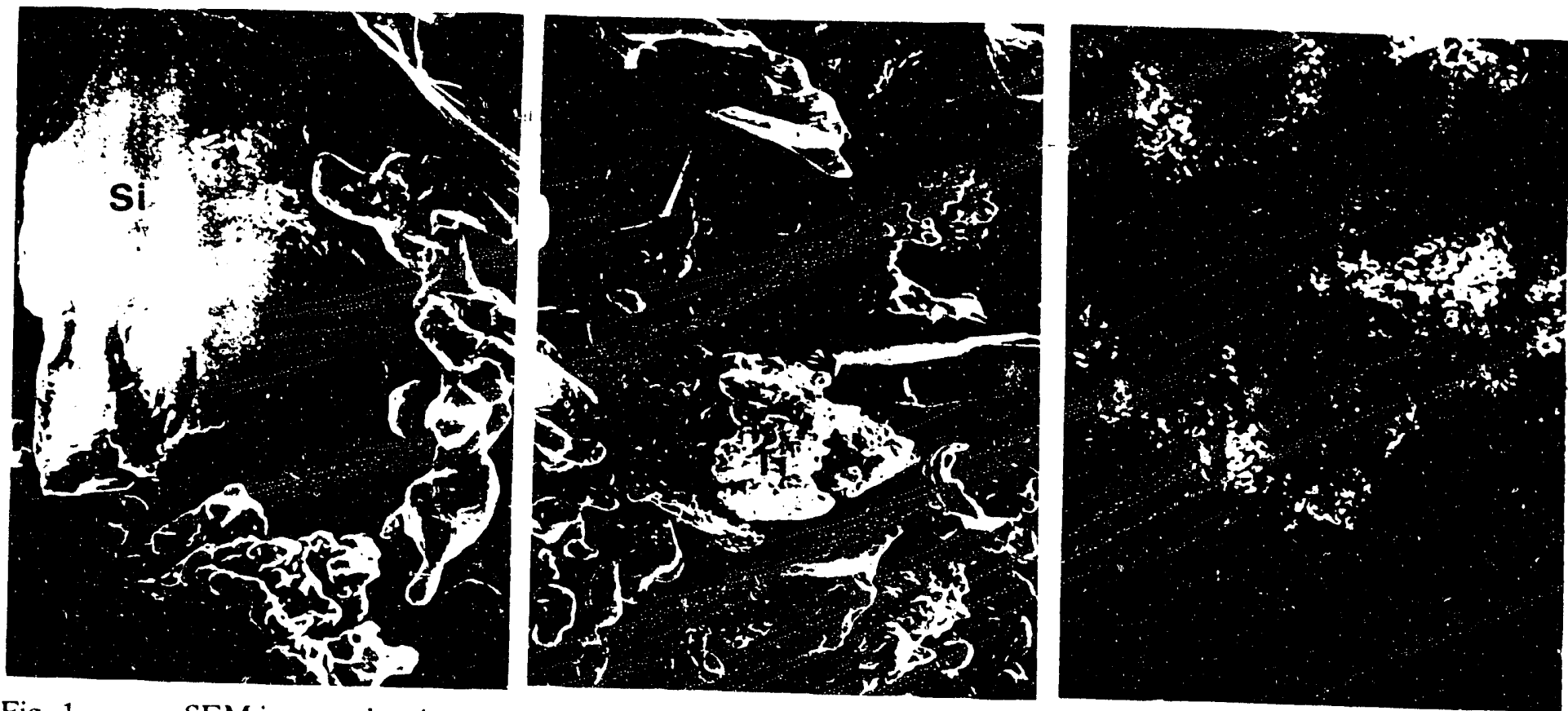

Fig. 1.

SEM images showing morphologies of Ti-Si powder mixtures: (a) coarse (b) medium, and (c) fine powders. Si particles are generally blocky single crystals and have a shiny contrast, while Ti particles are rounded polycrystalline aggregates with grainy contrast.

\section{RESULTS}

The overall results of shock recovery experiments, characterized based on optical and SEM analysis are illustrated in the reaction map in Figure 2. For medium morphology powders. MB-B experiments showed complete reaction in samples with $47 \%$ porosity, and no reaction in samples with $36 \%$ porosity. The PIB$B$ experiments showed no reaction in samples with $41 \%$ and $47 \%$ poronty, but complete reaction with $55 \%$ porosity. The reaction trends for medium morphology powders were used (o) guide experiments on fine and coarse morphology powders. However, no ractions were observed with coarse powders for MB-B experiments with $47 \%$ porosity, and PB-B experiments with $55 \%$ porosity. likewise no reactions were observed with fine powders for PB-B experiment with $55 \%$ porosity, while only localized reactions in peripheral edge regions of the compacts were observed for MB-B experiment with $47 \%$ porosity.

Time-resolved experiments (discussed elsewhere in this proceedings') were performed primarily on medium morphology li-Si powders at shock pressures up to 3 GPa. The results of lime-resolved experiments concur with the recovery experiments. and provide clear evidence of the occurrance on shoch-induced chemical retertions in Ti-Si powder mistures.
In general, the microstructure of the fully reacted samples showed an equiaxed grain structure, along with presence of spherical voids, typical of a fully reacted, melted, and resolidified material. The size of the equiaxed $\mathrm{Ti}_{5} \mathrm{Si}_{3}$ grains was measured to be $\approx 10 \mu \mathrm{m}$. A typical fully reacted microstructure is shown in Figure 3.

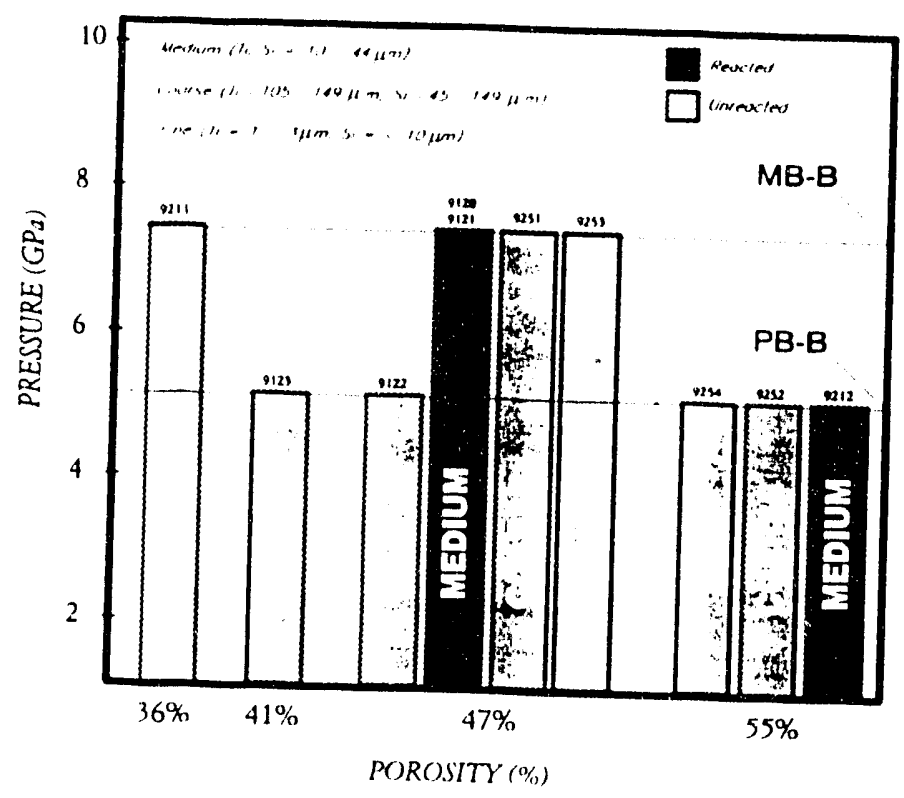

Fig. 2. Reaction matp showing affect of in a. densits. pouder morpholonge and combitions. 


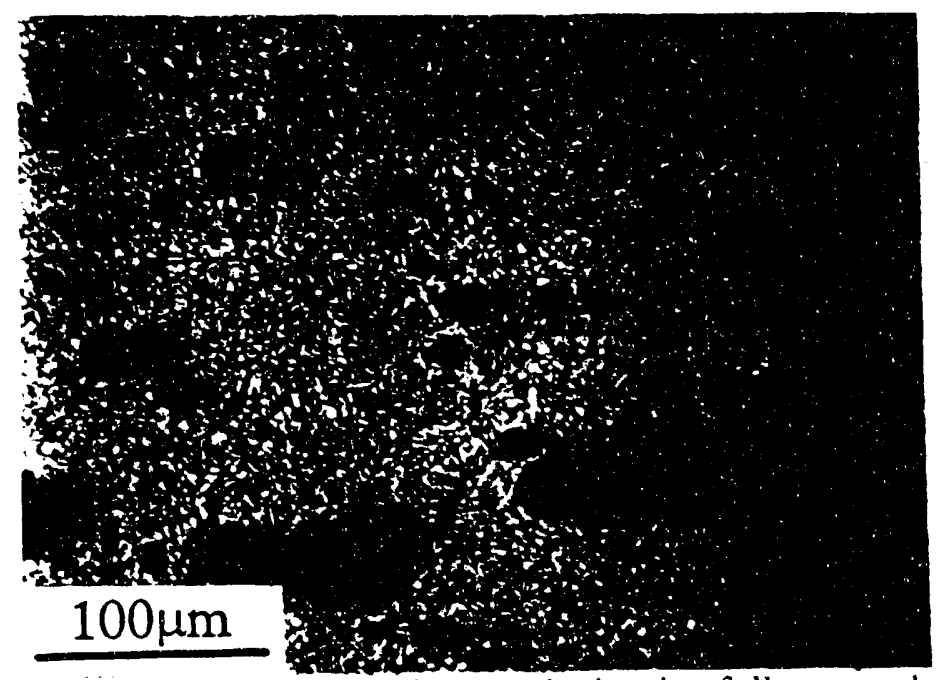

Fig. 3. Optical micrograph showing fully reacted microstructure.

Unreacted samples from experiments performed at shock conditions below the threshold are of principal interest in the present work. Such samples provide the configuration of powder mixtures in the shockcompressed state at various stages prior to inception of reaction. In order to compare the microstructure resulting from the effects of different variables, analysis was performed along identical regions of every microstructural compact, namely the central bulk area.

The most revealing effects are observed in samples of the three different morphologies, packed at similar density in the PB-B shock recovery fixture; the three corresponding optical micrographs are shown in Figure $4(a-c)$. The grainy-contrast fine, medium, and coarse morphology $\mathrm{Ti}$ particles in all cases show extensive deformation. The fine morphology Ti particles are also seen to form large agglomerates $\approx 200 \mu \mathrm{m}$ diameter. The shiny-contrast fine morphology $\mathrm{Si}$ particles show extensive deformation and flow around $\mathrm{Ti}$ particles (Fig. 4(a)). On the other hand the shinycontrast coarse Si particles show extensive fracture and fragmentation (Fig. 4(b)). The medium morphology Si powders show some cracking, as well as deformation and flow, the latter case observed particularly when $\mathrm{Si}$ is isolated and surrounded by Ti particles (Fig. 4 (c)).

The effect of shock pressure was best revealed on medium morphology Ti-Si powders. Optical micrographs of powders shock-compressed with the low pressure PB$B$ fixture and the higher pressure MB-B fixture are shown in Figure $5(a, b)$. While extensive deformation of the grairy-contrast Ti particies is commonly observed in both micrographs, the mixtures shock-compressed with the higher pressure MB-B fixture (Fig. o(b)) show more cracking than the those with the PB-B fixture. There is also evidence of possible melting of $\mathrm{Si}$, in certain localized regions of the $\mathrm{MB} B \mathrm{~B}$ - cimples.
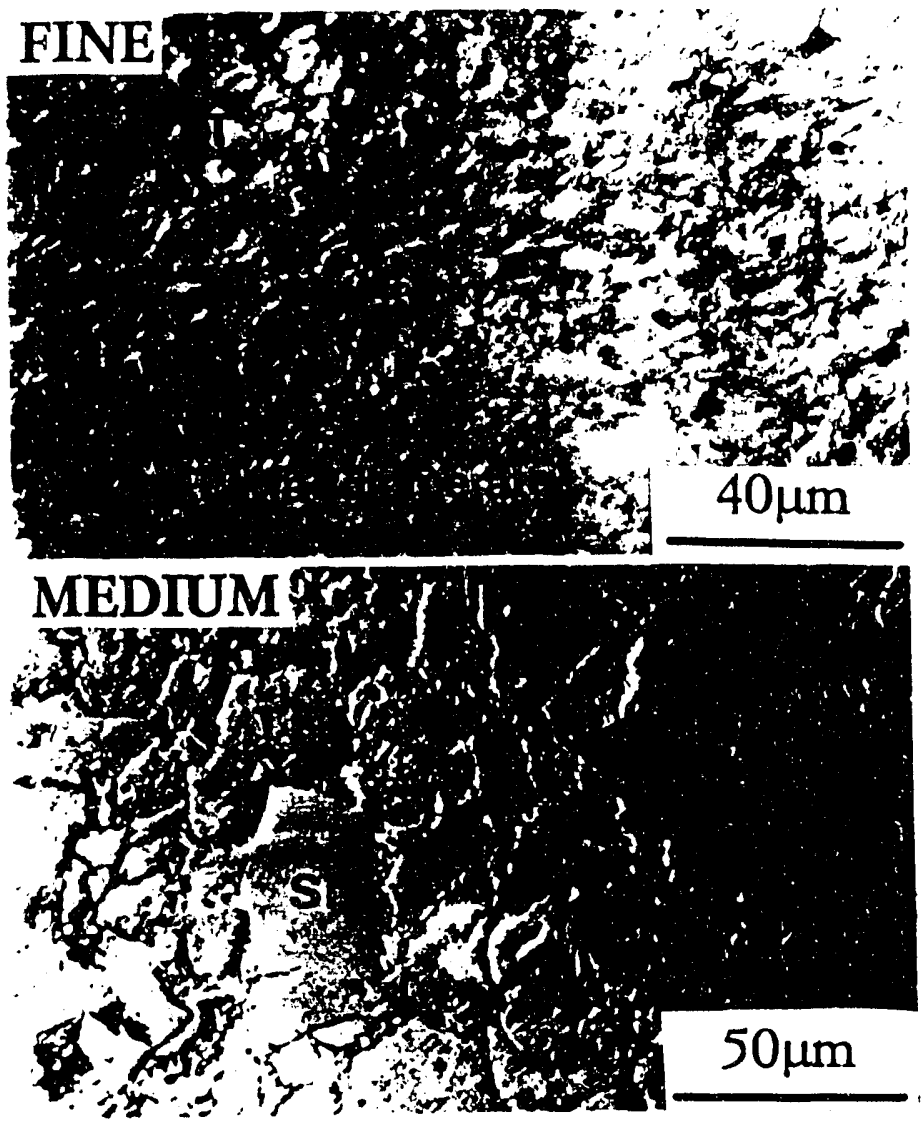

\section{COARSE}

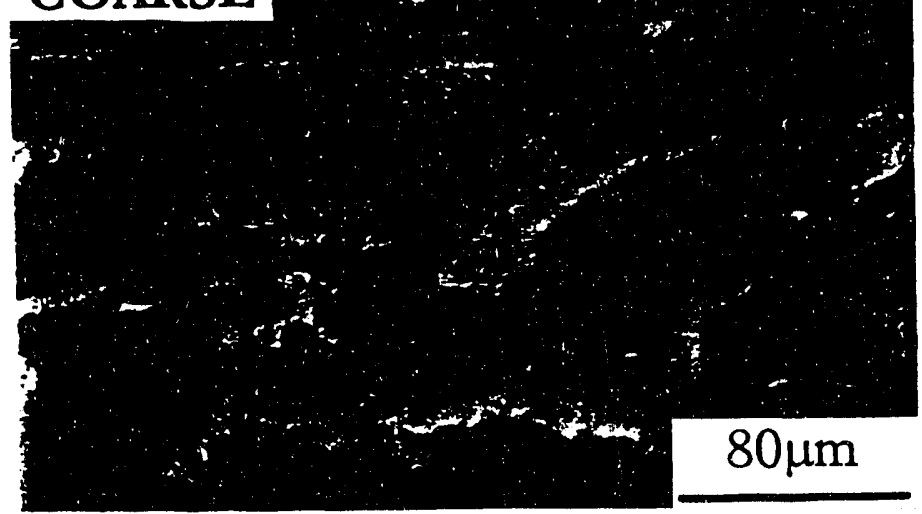

Fig. 4. Optical micrographs of tine, medium, and coarse morphology powders shock compressed with $\mathrm{PB}$ B fixture at same packing density.

\section{DISCUSSION}

The overall scenario revealed by recovery experiments illustrates that shock-induced chemical reactions in Ti-Si powder mixtures occur predominately with medium morphology powders. The reaction thresholds for medium morphology powders are shock conditions generated with $P B-B$ system with initial porosity of $5.5 \%$, or with MB-B system and $47 \%$ initial 

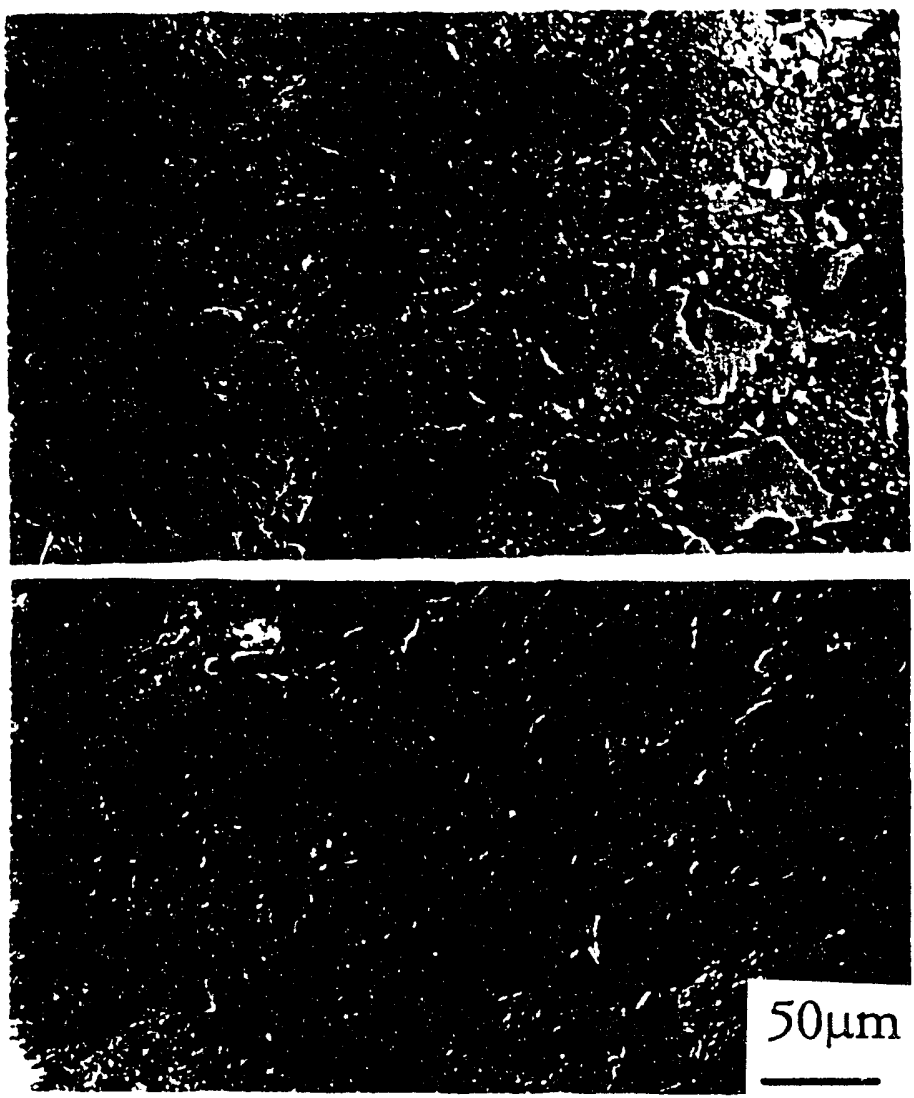

Fig. 5. Optical micrographs of powders shockcompressed with the low pressure PB-B fixture and the higher pressure MB-B fixture.

porosity. The picture emerging from the shockcompressed unreacted configuration of $\mathrm{Ti}$-Si powder mixtures provides clues of mechanistic processes that cause reactions in medium morpholugy powders and not in fine or coarse morphology powders. As shown in the micrographs in Figures 4 and 5, both $\mathrm{Ti}$ and $\mathrm{Si}$ medium morphology powders simultaneously undergo extensive deformation and flow leading to more intimate mixing between them. In contrast coarse morphology Si powders fracture and fragment at low stresses, prior to deformation of $\mathrm{Ti}$ particles, therefore, there is only limited mixing between the deformed $\mathrm{Ti}$ and $\mathrm{Si}$ fragments. Fine morphology $\mathrm{Ti}$ and Si powders are expected to undergo extensive deformation, and therefore the greatest propensity for reaction initiation. However, while fine $\mathrm{Si}$ particles do show extensive deformation and flow, the fine Ti particles tend to agglomerate, thereby limiting interparticle mixing.

\section{Mechanistic Considerations}

Simultaneous deformation of constituents is therefore. the important property needed to provide an ideal contiguration for intiation of shock-induced chemical reatoms. Morphological variations and porosity affect reaction initiation characteristics. by altering simultaneous deformability of the constituents. The deformation response of $\mathrm{Si}$ is also different when it is shock-compressed with other metals in a binary mixture, e.g., with $\mathrm{Ni}, \mathrm{Nb}$, Mo, instead of $\mathrm{Ti}$. Prior work ${ }^{3.6}$ shows that $\mathrm{Ni}-\mathrm{Si}$ and $\mathrm{Ti}-\mathrm{Si}$ systems have the highest propensity for reaction initiation, while $\mathrm{Nb}-\mathrm{Si}$ and Mo-Si systems have the lowest propensity. The Ni$\mathrm{Si}$ and $\mathrm{Ti}-\mathrm{Si}$ systems are favored because of the small difference in the yield strength of constituents which allows simultaneous deformation, plastic flow, and mixing to occur. In contrast, large yield strength differences anıngst constituents in Mo-Si and $\mathrm{Nb}-\mathrm{Si}$, inhibit complete mixing since the metal constituent has deform at higher stresses, and then mix with fragments of the brittle Si. Thus, simultaneous deformation and mixing is the first step towards providing the configuration for initiation of shock-induced chemical reactions consistent with Graham's CONMAH model?

\section{SUMMARY}

Shock-induced chemical reactions in Ti-Si powder mixtures occur at lower thresholds with medium morphology powders. In contrast, mixing is inhibited with coarse and fine powders due to fragmentation or agglomeration problems which limit the propensity for reaction intiation. Effects of powder morphology, initial porosity, and shock conditions, on resulting microstructure of shock-compressed unreacted Ti-Si powders, reveal the importance of the deformation response $\mathrm{Si}$, and its subsequent mixing with $\mathrm{Ti}$, in providing the configuration needed for reaction initiation.

\section{REFERENCES}

1. O. Kubaschewski and C.B. Alcock, Metallurgical Thermochemistry, 5th ed, Pergamon Press, 1979.

2. B.R. Krueger, A.H. Mutz, and T. Vreeland, Jr., Met. Trans., 23A, 55 (1991).

3. E. Dunbar, R.A. Graham, G.T. Holman, M.U. Anderson, and N.N. Thadhani, "Time-resolved Pressure Measurements in Chemically Reacting Powder Mixtures," to be published, this volume.

4. R.A. Graham, "Explosive Processing Methods," in High Pressure Explosive Processing of Ceramics, eds. K.A. Graham and A.B. Sawaoka, Trans Tech Publications, 1987, pp. 17-64.

5. L..H. Yu, Ph.D. dissertation, New Mexico Tech, Socorro, New Mexico, 1992.

6. V.N. Thadhani, Progress in Matls. Sci., 37( 2 ). $117(1993)$.

7. R.A. Graham. "Solids Under High Pressure Shock Compression: Mechanics Physics, and (hemistry." Springer Verleg, 1902. 

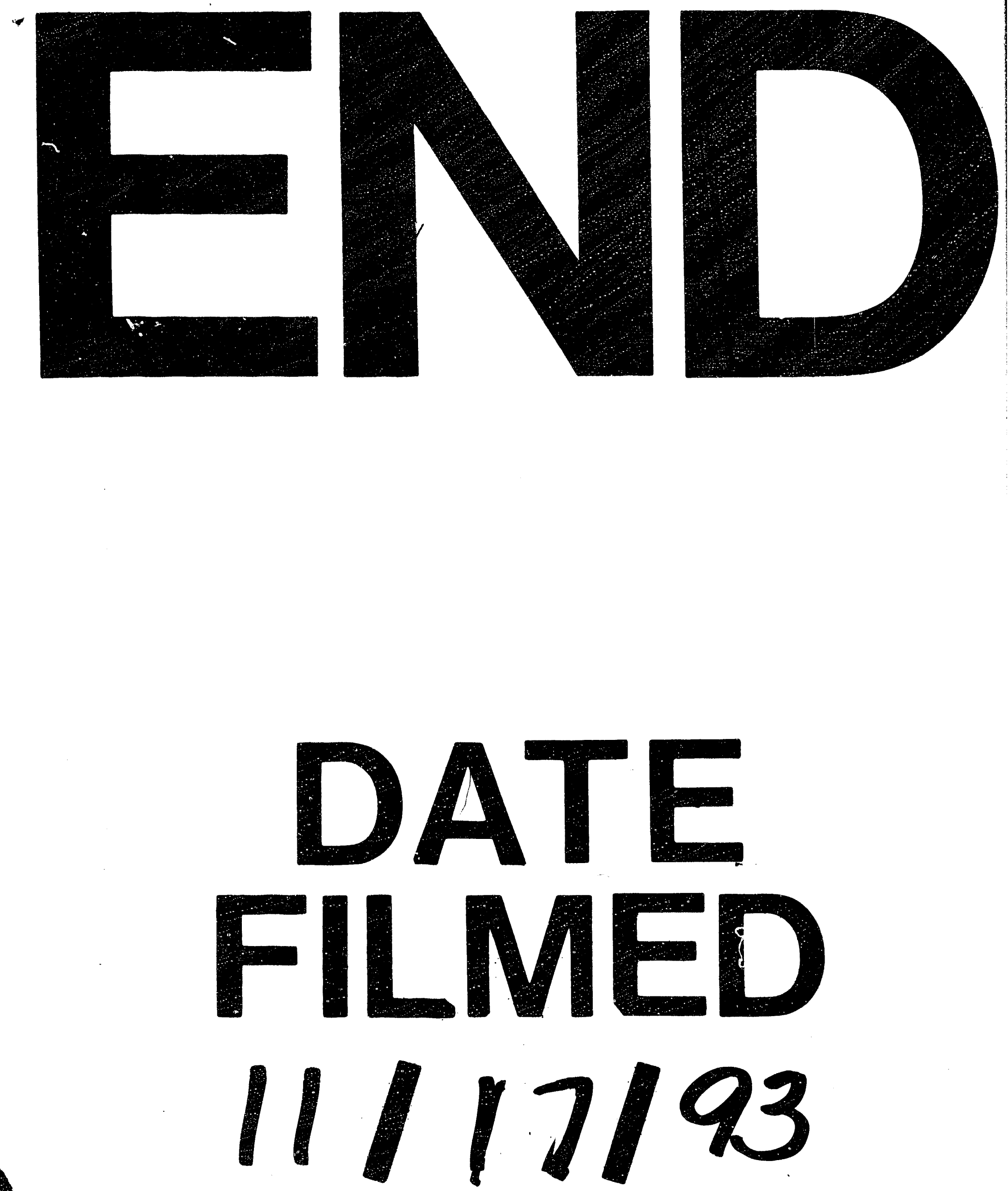
